Karine Béranger - Bernard Barnier •

Sergei Gulev · Michel Crépon

\title{
Comparing 20 years of precipitation estimates from different sources over the world ocean
}

Published online: 4 January 2007

(C) Springer-Verlag 2007

Unfortunately, an error occurred in Fig. 2.

Figure 2e and $\mathrm{f}$ (page 111) that should, in principle, show the precipitation fields of ECMWF and NCEP is exactly the same as Fig. 2c and d, which shows precipitation from MSU and CMAP.

The correct Fig. 2e,f:

Responsible editor: Jörg-Olaf Wolff

The online version of the original article can be found at http://dx. doi.org/10.1007/s10236-006-0065-2.

K. Béranger $(\triangle)$

ENSTA, UME, Chemin de la Hunière,

91761 Palaiseau Cedex, France

e-mail: Karine.Beranger@ensta.fr

Tel.: +33-169319753

Fax: +33-169319997

B. Barnier

LEGI-IMG, CNRS UMR 5519,

BP 53, 38041 Grenoble Cedex, France

S. Gulev

P. P. Shirshov Institute of Oceanology,

RAS, 36 Nakhimousky ave.

117851, Moscow, Russia

M. Crépon

LOCEAN,

Tour 45-55, 4e Etage, 4 Place Jussieu,

75252 Paris Cedex 05, France 
PRECIPITATION (mm/yr)

ECMWF REANALYSIS, CLIMATOLOGICAL MEAN (1980-93)

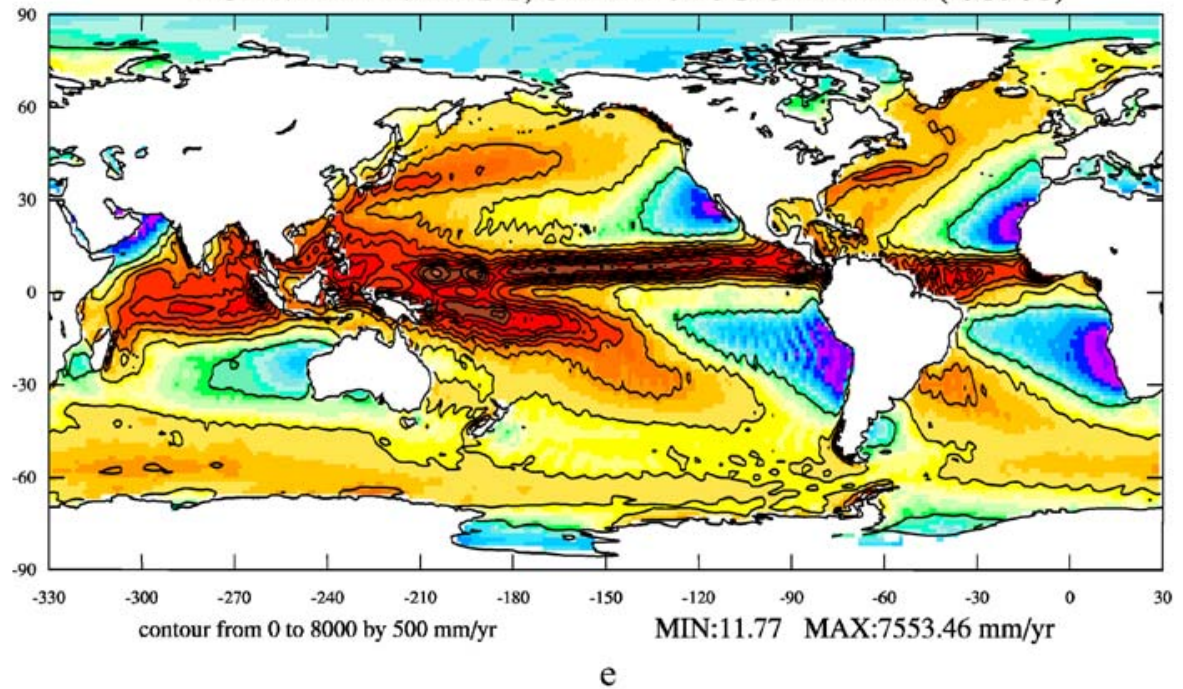

PRECIPITATION (mm/yr)

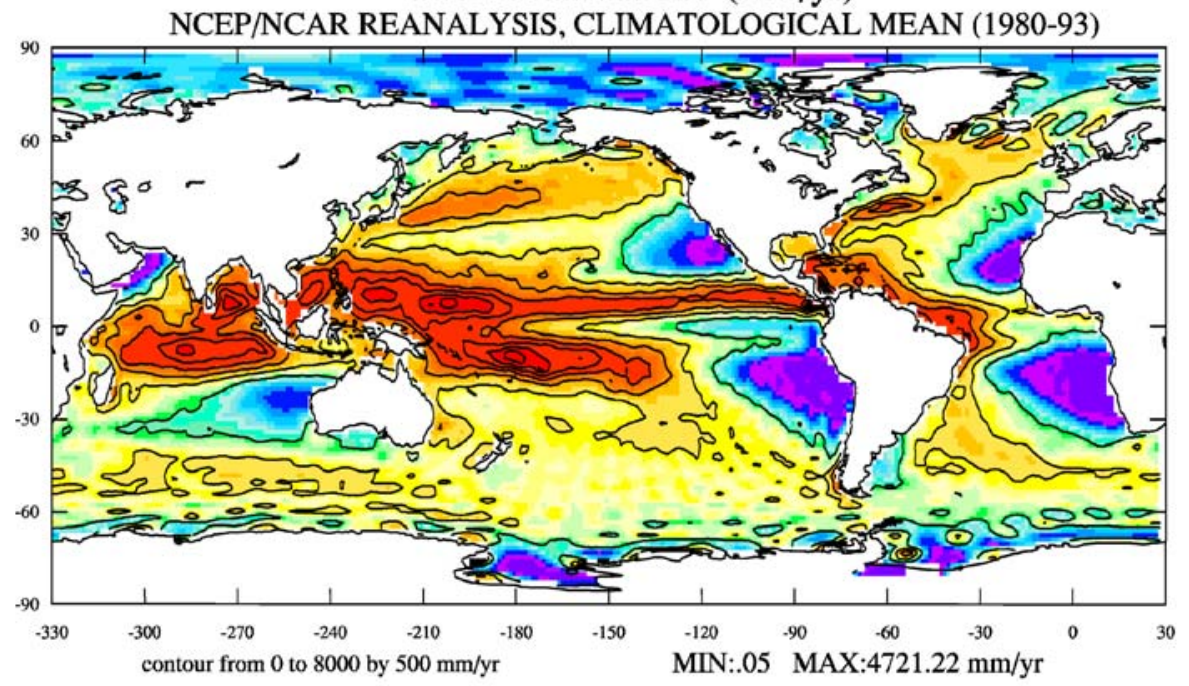

f

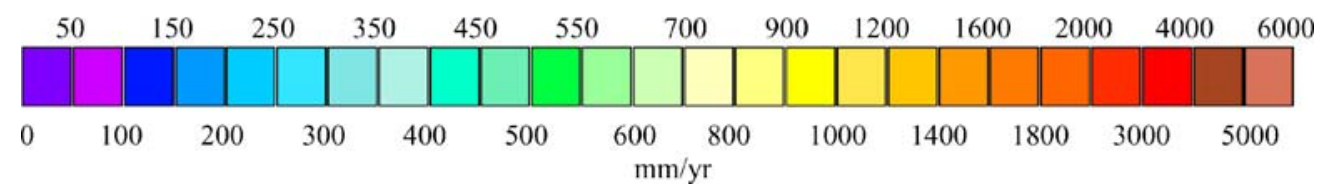

